\title{
Possible Mechanism of Symptomatic Improvement with IgG Antibody- guided Exclusion Diet in Inflammatory Bowel Disease and Irritable Bowel Syndrome
}

\section{Hulya Uzunismail*}

Department of Internal Medicine, Istanbul University, Istanbul, Turkey

*Corresponding author: Hulya Uzunismail, Internist and Gastroenterologist, Department of Internal Medicine, Cerrahpasa Medical School, Retired from Istanbul University, Istanbul, Turkey, E-mail: hulyauzunismail@gmail.com

Received date: November 20, 2018; Accepted date: November 26, 2018; Published date: December 03, 2018

Copyright: $\odot 2018$ Uzunismail $\mathrm{H}$. This is an open-access article distributed under the terms of the Creative Commons Attribution License, which permits unrestricted use, distribution, and reproduction in any medium, provided the original author and source are credited.

\begin{abstract}
Recently, symptomatic improvements with food exclusion diet based on immunoglobulin G (lgG) antibodies have been reported in both inflammatory bowel disease (IBD) and irritable bowel syndrome (IBS). But the mechanisms of these results have not been explained yet. The common point of these disorders is the important role of mast cells in their pathogenesis. Mast cells are widely present in intestinal mucosa and they are responsible for both intestinal health and disorder status. IgG-antigen immune complexes can stimulate mast cells by binding to their activating Fcy receptors. Increased IgG-food antigen complexes due to increased food specific IgG antibodies can cause more mast cell activation. Elimination of these foods may help symptomatic improvement in patients with IBD and IBS by reducing the amount of immune complexes because of lack of the food antigen part of them.
\end{abstract}

Keywords: Inflammatory bowel disease; Irritable bowel syndrome; Mast cells; Immunoglobulin G; Food exclusion

\section{Introduction}

From the beginning of this century, food specific immunoglobulin $\mathrm{G}$ (IgG)-guided exclusion diet has been found to be associated with symptomatic improvements in different disorders such as treatment resistant delayed food allergy [1], irritable bowel syndrome (IBS) [2-6], chronic diarrhoea [7], Crohn's disease (CD) [8-11], ulcerative colitis (UC) [12], migraine $[6,13,14]$ and asthma [15]. The negative effects of IgG-positive foods and additives on the clinical course and laboratory findings were detected after the provocation of them in Crohn's disease patients by our clinical study, as well [16]. In three [3,9,10] of them, food exclusion diet applied according to the IgG4 antibody values. Normally, healthy individuals have IgG antibodies against food antigens [17]. In this diet, foods which have increased IgG levels above the cut-off level of healthy individuals are excluded, these foods are also called "IgG-positive".

The common feature of many of the above-mentioned diseases such as IBS [18,19] inflammatory bowel disease (IBD) [20,21], migraine [22] and asthma $[23,24]$ is that mast cells play an important role in their pathogenesis. Although mast cells have long been recognized as only a central player in IgE-mediated allergic reactions, in last two decades it has been understood that they are multifunctional immune cells which are effective in several health and disease status [24,25]. Mast cells play a critical role in innate and adaptive immunity [23-27] and can regulate functions of immune cells such as dendritic cells, monocytes/macrophages, granulocytes, T cells, B cells, fibroblasts [26,27]. Mast cells also counteract regulatory T (Treg) cell functions [28-30]. For this reason mast cells play an important role in the pathogenesis of autoimmune disorders because Treg cells prevent autoimmune diseases by maintaining self-tolerance and suppressing effector T (Teff) cells $[29,30]$.

\section{Possible mechanism of IgG-food exclusion diet}

Many stimuli other than IgE, such as $\operatorname{IgG}$, IgA, complements, cytokines, bacterial components neuropeptides, hormones can activate mast cells $[23,29,31]$. Classically upon activation, mast cells release preformed mediators stored in the granules such as histamine, serotonin, tryptase and newly synthesised mediators like prostaglandins, leukotrienes, cytokines, chemokines, growth factors $[23,29,31]$.

Mast cells can be differentially activated to release distinct patterns of mediators or cytokines $[23,26]$ depending on the type and strength of the activating stimuli [26]. For example, mast cells can be activated with selective release of mediators without degranulation [23]. In nonallergic responses mast cells are more prevalently activated by IgEindependent factors [29]. IgG immune complexes are between these factors and activate mast cells by binding to activating $\mathrm{Fc} \gamma$ receptors (FcRs) on their surfaces $[24,27,29]$. Mast cells have both activating and inhibitory Fc $\gamma$ Rs, [27] because most of the activating Fc $\gamma$ Rs are in low affinity, IgG antibodies generate immune complexes before stimulating them [27]. Food and food additive antigens activate mast cells often mediated by IgG antibodies [31]. In this case, symptomatic improvements with exclusion of IgG positive foods may be due to decreased mast cell activation, related to reduce complexes because antigen parts of them do not exist.

\section{Mast Cell-IBD and IBS Relationship}

Mast cells are predominantly present at barrier sites of the body such as the skin, gastrointestinal, respiratory and urinary tracts. Mast cells are mainly located in the lamina propria of the intestine and 2-3\% of all cells in this region are mast cells [25]. They are also found in the intraepithelial, smooth muscle and serosal layers [18,19]. They communicate with the adjacent epithelial, neuronal, smooth muscle and other immune cells when they are activated [18]. 
Mast cells involve in physiological processes of the intestine such as regulating blood flow, permeability, secretion, peristalsis, and also host defence against pathogens [25].These physiological responses are related to regulating effects of mast cell mediators, released by IgE or non-IgE-dependent stimulations [18]. Small amount of immune complexes which generate from low-level $\operatorname{IgG}$ antibodies and their food antigens may be one of these stimulators for physiological functions in healthy individuals.

Recently, increased intestinal mast cell activation has been considered to play an important role in the pathogenesis of both IBD $[20,21]$ and IBS $[18,19]$. The relationship between increased mast cell mediators and pathophysiologic factors was mostly investigated in IBS and found to be related increased excitability of senso-secreto-motor neurons and visceral hypersensitivity, disturbed motility, and altered secretion $[18,19]$. These factors are responsible for abdominal pain, bloating, and diarrhoea in patients with IBS and most likely IBD to a certain degree. When IgG antibodies, especially against to very frequently consumed foods are increased, immune complexes generated them may cause more mast cell activation and hence more symptoms. In addition, reduced junctional adhesion molecule-A expression due to mast cell tryptase was shown in IBS patients [32]. As a result, increased mast cell activation may cause increased bacterial, food and additive antigen absorption due to increased possible mechanism of IgG-food exclusion diet intestinal permeability which is also one of important pathophysiologic factors for both IBS and IBD.

\section{Is there a difference between IBD and IBS in terms of IgG positive foods?}

Since 2005, I have observed symptomatic improvements in many patients with functional and autoimmune gastrointestinal disorders such as overlap between irritable bowel syndrome and functional dyspepsia (IBS-FD), CD and UC.

According to my personal data; while some frequently utilized foods or thickening food additives have high positivity rates, near or more than $40 \%$ and reach to $65 \%$ as in wheat, hen's egg, guar gum (E412) and agar (E406), some others have less than $5 \%$ as in potato, olive, black tea in all three diseases. These high rates in all diseases have been also seen in rarely utilized food like vanilla and some types of mushrooms.

Some foods have higher positivity rates in both CD an IBS-FD than UC like yeast (baker's), sunflower seed, cow's milk and products, tomato, coffee, garlic and pistachio. However, some others have higher positivity rates in CD than both IBS-FD and UC as in maize, peach and honey mixture.

In general, the number of IgG positive foods is highest in $\mathrm{CD}$, followed by FDIBS and at least in UC. IgG positivity does not seem to be related the eating frequency and amount of foods and also presence either autoimmune or functional gastrointestinal disease.

\section{Objections to food specific IgG antibody tests}

Although IgE and IgG antibodies and their receptors on mast cells were detected in nearly same years e.g., in late 1960, early 1970's, [27] IgG-mediated mast cell reactions have not fully been understood [24]. Nevertheless recently IgG dependent mast cell activation has begun to be considered as allergies [27,31]. On the other hand, the importance of food specific IgG antibodies has not accepted by some physicians because of this antibodies present in healthy individuals in small amounts. Additionally, some $\operatorname{IgG}$ positive foods may not cause symptoms because their complexes engage inhibiting $\mathrm{Fc} \gamma \mathrm{Rs}$ and thus cause confusion.

Reported good results of studies depending on IgG4 antibodies is another cause of confusion and also objection. This subclass of IgG antibodies are accepted as "blocking antibodies" especially in the context of allergies because they can prevent excessive immune responses against sterile antigens [33]. The explanation of their good results may be presence both IgG and IgG4 positivity for some of the same food antigens especially the ones consumed frequently such as gluten, yeast, milk and products, and egg.

\section{Conclusion}

The possible underlying mechanism of symptomatic alleviations of both IBD and IBS with exclusion of IgG positive foods is due to decreased mast cell activation and reduction of the immune complexes as a result of the lack of food antigen fragment of them. Food-specific IgG antibody guided exclusion diets may give a chance either as a main therapy in IBS or as an adjuvant therapy in IBD. This type of diet may even be useful in mast cells activation syndromes. Future studies seem to be necessary to definitely confirm this situation. Finally, IgG-IgG4 complexity needs further investigation with exclusion diet studies comparing IgG and IgG4 antibodies.

\section{References}

1. Dixon HS (2000) Treatment of delayed food allergy based on specific immunoglobulin G RAST testing. Otolaryngol Head Neck Surg 123: 48-54.

2. Atkinson W, Sheldon TA, Shaath N, Whorwell PJ (2004) Food elimination based on IgG antibodies in irritable bowel syndrome: a randomized controlled trial. Gut 53: 1459-1464.

3. Zar S, Mincher L, Benson MJ, Kumar D (2005) Food-specific IgG4 antibody-guided exclusion diet improves symptoms and rectal compliance in irritable bowel syndrome. Scand J Gastroenterol 40: 800-807.

4. Yang CM, Li YQ (2007) The therapeutic effects of elimination allergic foods according to food-specific IgG antibodies in irritable bowel syndrome. Zhonghua Nei Ke Za Zhi 46: 641-643.

5. Guo H, Jiang T, Wang J, Chang Y, Guo H, et al. (2012) The value of eliminating foods according to food specific immunoglobulin G antibodies in irritable bowel syndrome with diarrhea. J Int Med Res 40: 204-210.

6. Aydinlar EI, Dikmen PY, Tiftikci A, Saruc M, Aksu M, et al. (2013) IgGbased elimination diet in migraine plus irritable bowel syndrome. Headache 53: 514-525.

7. Ou-Yang WX, You JY, Duan BP, Chen CB (2008) Application of food allergens specific IgG antibody detection in chronic diarrhea in children. Zhongguo Dang Dai Er Ke Za Zhi 10: 21-4.

8. Bentz S, Hausmann M, Piberer H, Kellermeier S, Paul S, et al. (2010) Clinical relevance of IgG antibodies against food antigens in Crohn's disese. A doble-blind cross-over diet intervention study. Digestion 81: 252-264.

9. Rajendran N, Kumar D (2011) Food-specific IgG4-guided exclusion diets improve symptoms in Crohn's disease: a pilot study. Colorectal Dis 13: 1009-1013.

10. Gunasekeera V, Mendall MA, Chan D, Kumar D (2016) Treatment of Crohn's Disease with an IgG4-Guided Exclusion Diet: A Randomized Controlled Trial. Dig Dis Sci 61: 1148-1157.

11. Wang G, Ren J, Li G, Hu Q, Gu G, et al. (2018) The utility of food antigen test in the diagnosis of Crohn's disease and remission maintenance after exclusive enteral nutrition. Clin Res Hepatol Gastroenterol 42: 145-152. 
Citation: Uzunismail H (2018) Possible Mechanism of Symptomatic Improvement with IgG Antibody-guided Exclusion Diet in Inflammatory Bowel Disease and Irritable Bowel Syndrome. J Inflam Bowel Dis Disor 3: 128. doi:10.4172/2476-1958.1000128

Page 3 of 3

12. Jian L, Anqi H, Gang L, Litian W, Yanyan X, et al.(2018) Food Exclusion Based on IgG Antibodies Alleviates Symptoms in Ulcerative Colitis: A Prospective Study. Inflamm Bowel Dis 24: 1918-1925

13. Arroyave Hernández CM, Echavarría Pinto M, Hernández Montiel HL (2007).Food allergy mediated by IgG antibodies associated with migraine in adults. Rev Alerg Mex 54: 162-168.

14. Alpay K, Ertas M, Orhan EK, Ustay DK, Lieners C, et al. (2010) Diet restriction in migraine, based on IgG against foods: a clinical doubleblind, randomised, cross-over trial. Cephalalgia 30: 829-837.

15. Virdee K, Musset J, Baral M, Cronin C, Langland J (2015) Foodspecific IgG Antibody-guided Elimination Diets Followed by Resolution of Asthma Symptoms and Reduction in Pharmacological Interventions in Two Patients: A Case Report Glob Adv Health Med 4: 62-66.

16. Uzunismail H, Cengız M, Uzun H, Ozbakir F, Göksel S, et al. (2012) The effects of provocation by foods with raised IgG antibodies and additives on the course of Crohn's disease. Turk J Gastroenterol 23: 19-27.

17. Husby S, Oxelius VA, Teisner B, Jensenius JC, Svehag SE (1985) Humoral immunity to dietary antigens in healthy adults. Occurrence, isotype and IgG subclass distribution of serum antibodies to protein antigens. Int Arch Allergy Appl Immunol 77: 416-422.

18. Lee KN, Lee OY (2016) The Role of Mast Cells in Irritable Bowe Syndrome. Gastroenterol Res Pract 2016: 2031480.

19. Zhang L, SongJ, Hou X (2016) Mast Cells and Irritable Bowel Syndrome: From the Bench to the Bedside. J Neurogastroenterol Motil 22: 181-192.

20. He SH (2004) Key role of mast cells and their major secretory products in inflammatory bowel disease. World J Gastroenterol 10: 309-318.

21. Hamilton MJ, Frei SM, Stevens RL (2014) The multifaceted mast cell in inflammatory bowel disease. Inflamm Bowel Dis 20: 2364-2378.

22. Loewendorf AI, Matynia A, Saribekyan H, Gross N, Csete M, et al. (2016) Roads Less Traveled: Sexual Dimorphism and Mast Cell Contributions to Migraine Pathology. Front Immunol 7: 140.
23. Theoharides TC, Alysandratos KD, Angelidou A, Delivanis DA, Sismanopoulos N, et al. (2012) Mast cells and inflammation. Biochim Biophys Acta 1822: 21-33.

24. Caslin HL, Kiwanuka KN, Haque TT, Taruselli MT, MacKnight HP, et al. (2018) Controlling Mast Cell Activation and Homeostasis: Work Influenced by Bill Paul That Continues Today. Front Immunol 9: 868.

25. Bischoff SC (2009) Physiological and pathophysiological functions of intestinal mast cells. Seminars in Immunopathology 31: 185-205.

26. Galli SJ, Grimbaldeston M, Tsai M (2008) Immunomodulatory mast cells: negative, as well as positive, regulators of immunity. Nat Rev Immunol 8: 478-486.

27. Jönsson F, DaëronM (2012) Mast cells and company. Front Immunol 3: 16.

28. Piconese S, Gri G, Tripodo C, Musio S, Gorzanelli A, et al. (2009) Mast cells counteract regulatory T-cell suppression through interleukin-6 and OX40/OX40L axis toward Th17-cell differentiation. Blood 114: 2639-2648.

29. Walker ME, Hatfield JK, Brown MA (2012) New insights into the role of mast cells in autoimmunity: evidence for a common mechanism of action? Biochim Biophys Acta 1822: 57-65

30. Xu Y, Chen G (2015) Mast cell and autoimmune diseases. Mediators Inflamm 246126.

31. He SH, Zhang HY, Zeng XN, Chen D, Yang PC (2013) Mast cells and bas ophils are essential for allergies: mechanisms of allergic inflammation and a proposed procedure for diagnosis. Acta Pharmacol Sin 34: 1270-1283.

32. Wilcz-Villega EM, McClean S, O'SullivanMA (2013) Mast cell tryptase reduces junctional adhesion molecule-A (JAM-A) expression in intestinal epithelial cells: implications for the mechanisms of barrier dysfunction in irritable bowel syndrome. Am J Gastroenterol 108: 1140-1151.

33. Vidarsson G, Dekkers G, Rispens T (2014) IgG subclasses and allotypes: from structure to effector functions. Front Immunol 5: 520 